\title{
Analysis of Quality Improvement Priority for Construction PMIS
}

\author{
An, Hyo-Kyung ${ }^{1} \quad$ Lee, Seul-Ki ${ }^{1} \quad$ Lee, Hyoung-Lak ${ }^{1} \quad$ Yu, Jung-Ho ${ }^{2 *}$ \\ Graduate School, Kwangwoon University, Nowon-Gu, Seoul, 136-777, Korea ${ }^{1}$ \\ Department of Architectural Engineering, Kwangwoon University, Nowon-Gu, Seoul, 136-777, Korea ${ }^{2}$
}

\begin{abstract}
As one of the key IT applications, the project management information system (PMIS) played a significant role in construction management processes in Korea. On increasing use of PMIS, regular quality assessment to identify user's requirements of PMIS is necessary. However, there have been rare research efforts for quality assessment for the construction PMIS. This paper aims to propose a priority index of quality improvement for construction PMIS using the importance and satisfaction measures and to verify the discrimination power of the priority index by comparing it with other quality improvement priority index. In addition, this paper discusses some possible ways of PMIS quality improvement. The analysis of quality improvement priority was based on a questionnaire responded by 253 PMIS users (construction managers and constructors). The methods of PMIS improvement were based on the interviews with eight experts. These findings would be the foundation of further researches on PMIS quality improvement. However, more efforts are required to enhance the priority index, in terms of reflecting weighted values of quality assessment factors.
\end{abstract}

Keywords : project management information system, priority index, quality improvement

\section{Introduction}

\subsection{Background and Objective}

As there are many different participants who pursue diverse values, smooth information-sharing and communication among them is the most essential factor in the successful performance of construction projects, which means that an information system is required to support the related information-sharing and communication. In addition, to effectively manage the huge amounts of data generated in the course of the construction project management process, a systemic database should be built, and data should also be reprocessed in a

Received : June 30, 2011

Revision received : November 11, 2011

Accepted : November 23, 2011

* Corresponding author :Yu, Jung-Ho

[Tel: 82-2-909-5546, E-mail: myazure@kw.ac.kr]

(C)2012 The Korea Institute of Building Construction, All rights reserved. manner that is appropriate for a system in which user opinions can be reflected in real time [1,2]. To meet these demands, many studies have been conducted on the development and utilization of a Project Management Information System (PMIS) to support the entire process of a construction project [3]. On the other hand, the use of a PMIS has become not an option but a sine qua non for improving effectiveness and efficiency since it was stipulated as one of the main tasks of a construction project manager in Directives for Construction Projects enacted by Ministry of Construction and Transportation on Dec. 1, 2009 [1].

To ensure that users utilize PMIS more actively and achieve the objective of building the construction PMIS, a quality assessment from the users' perspective should be performed periodically, and a plan for quality improvement should be made based on the assessment. The activities for quality 
improvement usually proceed according to priority, taking into account the limits of the resources given. The priority planning is applied to the development process of a general information system $[4,5,6,7,8,9]$. Thus far, there have been few studies that attempt to draw a systemic priority for the quality improvement of construction PMS in current use. Likewise, there have been few studies to suggest a quality improvement plan according to priority.

Hence, a priority assessment method is based on importance and satisfaction measures by quality item as well as quality items appropriate for the construction PMIS quality assessment is presented in this paper. Moreover, the improvement plans for the quality factors that are determined to be more important will also be discussed. The quality improvement is expected to contribute to providing a discrimination power to the priority index. In addition, more important quality factors will be discussed to improve the PMIS, which will ultimately contribute to improving user satisfaction.

\subsection{Research Scope and Method}

The construction PMIS can be broadly divided into an Information System that is developed inhouse by the company using the system, an ASP based Information System that is developed and provided for wide use, and an Information System that is specialized to specific large projects. The scope of this research is restricted to the ASP based PMIS, which is widely used in the construction industry in Korea.

The procedures of this research are as follows (See Figure 1). The process of drawing the quality factors to be utilized for quality improvement priorities assessment of the PMIS was organized. Next, literature was reviewed to suggest a quality improvement priority index for the PMS based on the importance and satisfaction measures found in the literature, and then the quality improvement priority index was verified through a comparative analysis with the existing priority indices. Finally, based on the users' assessment, the quality improvement priorities were determined, and an approach to improving the important factors was also discussed.

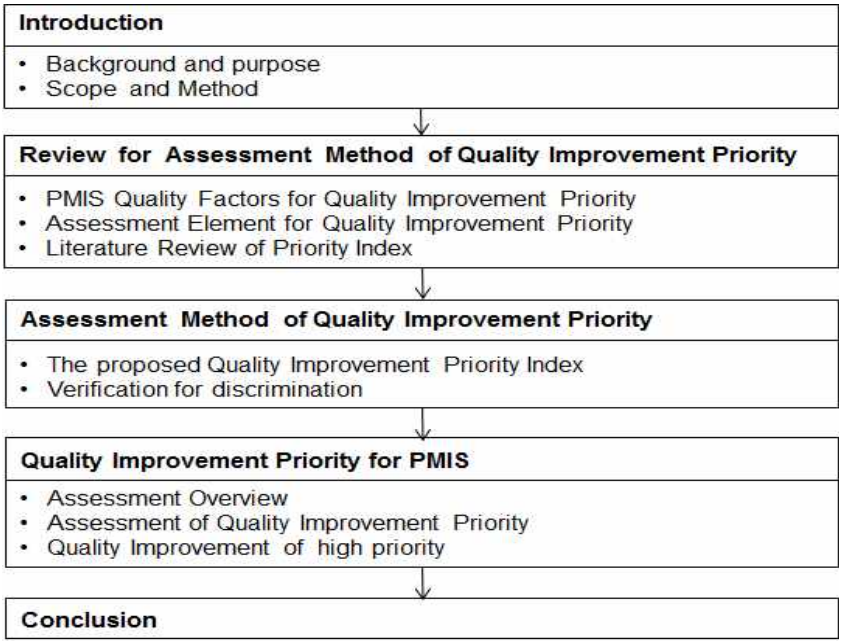

Figure 1. Research Process

For users' assessment, a questionnaire consisting of 23 questions was given to a total of 253 people. The opinions of users were reflected in the assessment. To discuss the factors ranked at the top on the list, 8 employees with more than 10 years of experience in charge of developing the PMIS were selected from among the developers and interviewed in written form.

\section{Assessment method of quality improvement priorities}

\subsection{Assessment items of quality improvement priorities}

The quality assessment items in the construction PMIS utilized in this research were drawn from the author' s preliminary research[10]. The processes of drawing the assessed items and of verifying reliability and validity can be summarized as follows:

1) Through the preliminary research on quality 
assessment of the Information System and successful cases $[11,12,13,14,15,16,17,18$, 19] the items that were possible to assess were collected, and then some of the items, which had a similar meaning and were redundant, or which were for a specific Information System, were eliminated based on the preliminary research. The characteristics of the construction industry and construction information management were reflected in a manner appropriate for the quality assessment of the construction PMS. A total of 25 assessment items were selected.

2) Interviews were conducted with 3 construction PMIS developers with 8 years of experience to ensure the validity of the content of the quality assessment items selected (redundancy and appropriateness). Through the interviews, 23 of the 25 originally selected items were finally selected.

3) To verify the compasition validity of 23 assessment items, an exploratory factor analysis (EFA) was performed. As a means of determining the number of factors, an eigenvalue is the factor by which the eigenvector is scaled when multiplied by the matrix. The higher the eigenvalue is, the better the distribution of the variables of a factor is explained. More than 1 was set as the measuring standard. In addition, factor loading was used to determine the importance of measured variables in the process of interpreting the EFA, and the factor loading value reflects the correlation between the common factor and an original variable. More than 0.5 was set as the measuring standard [20, 21, 22]. From the EFA results, 3 factors were derived, which were System Quality (5 assessment items), Information Quality (10 assessment items) and Service Quality (8 assessment items).
4) Cronbach' s $\alpha$ (alpha), a coefficient of reliability, was used to verify reliability of the assessment items of the construction PMIS. In general, if the Cronbach's $\alpha$ is shown to be higher than 0.6, reliability is acknowledged[23]. The Cronbach's $\alpha$ was shown to be $0.835,0.941$, and 0.926 for the factors of System Quality, Information Quality and Service Quality, respectively. Therefore, the assessment items of the construction PMS proposed in this paper can be considered statistically reliable. Table 1 shows the assessment items of the construction PMIS drawn this procedure.

Table 1. Factors for ASP based PMIS Quality

\begin{tabular}{|c|c|c|}
\hline Factor & & Assessment Items \\
\hline \multirow{5}{*}{$\begin{array}{l}\text { System } \\
\text { Quality } \\
(5)\end{array}$} & 1 & $\begin{array}{l}\text { PMIS should be compatible with other softwares } \\
\text { (e.g., such as Excel, P3, CAD) }\end{array}$ \\
\hline & 2 & $\begin{array}{l}\text { PMIS should connect to other IT tools (e.g., such as } \\
\text { PDA, RFID, USN) }\end{array}$ \\
\hline & 3 & $\begin{array}{l}\text { Data input/output functions should be operated easily } \\
\text { (e.g., up/download, printing) }\end{array}$ \\
\hline & 4 & Access to system should be not difficult \\
\hline & 5 & System should maintain the stable state \\
\hline \multirow{10}{*}{$\begin{array}{l}\text { Information } \\
\text { Quality } \\
\text { (10) }\end{array}$} & & $\begin{array}{l}\text { System functions and configuration should be related } \\
\text { to required information }\end{array}$ \\
\hline & 2 & $\begin{array}{l}\text { System screen configuration or document formats } \\
\text { should be suitable for information use }\end{array}$ \\
\hline & 3 & Search of information should be easy \\
\hline & 4 & PMIS should offer information to users on real time \\
\hline & 5 & Information in system should be reliable \\
\hline & 6 & $\begin{array}{l}\text { Information in system could be used without } \\
\text { correction }\end{array}$ \\
\hline & 7 & Information in system should be sufficient \\
\hline & 8 & $\begin{array}{l}\text { Information in system should be related to user's } \\
\text { task }\end{array}$ \\
\hline & 9 & $\begin{array}{l}\text { Information in system should be related to project } \\
\text { characteristics and user's role }\end{array}$ \\
\hline & 10 & $\begin{array}{l}\text { Options for information usage should be various } \\
\text { depending on the user's task }\end{array}$ \\
\hline \multirow{8}{*}{$\begin{array}{l}\text { Service } \\
\text { Quality } \\
\text { (8) }\end{array}$} & 1 & $\begin{array}{l}\text { Reaction of PMIS service provider should be quick } \\
\text { in the situation }\end{array}$ \\
\hline & 2 & $\begin{array}{l}\text { Technical support of PMIS service provider for } \\
\text { maintenance and repair should be quick. }\end{array}$ \\
\hline & 3 & $\begin{array}{l}\text { Education for PMIS users should be provided } \\
\text { adequately }\end{array}$ \\
\hline & 4 & $\begin{array}{l}\text { User's manual and advice should be provided } \\
\text { adequately during use }\end{array}$ \\
\hline & 5 & $\begin{array}{l}\text { PMIS service provider should possess knowledge of } \\
\text { construction field }\end{array}$ \\
\hline & 6 & User should feel safe regarding data security \\
\hline & 7 & User should trust capability of PMIS service provider \\
\hline & 8 & PMIS service provider should be faithful \\
\hline
\end{tabular}

ASP (Application Service Provider), PMIS (Project Management Information System) 


\subsection{Assessment factors in quality improvement priorities}

The Importance-Performance Analysis (IPA) technique was first applied to analyze automobile performance. Since then, it has been applied in various studies to derive quality improvement priorities in education, sports, psychology, etc. The IPA technique is an assessment technique used to simultaneously compare and analyze the importance and performance of each attribute in order to measure the user' $\mathrm{s}$ satisfaction. Each of the compared values falls into one of four quadrants by characteristic of importance and satisfaction, and thus the IPA model enables managers to get a visual understanding of the items that need improving. However, Tonge and Moore [29] explained that it is more appropriate to focus on satisfaction, which measures the user' $\mathrm{s}$ experience, than on performance, which measures the quality of management, when deriving the priority for service quality improvement [25]. On this basis, the Importance-Satisfaction Analysis (ISA) was applied in many different studies that evaluated the quality based on the users' experience, including studies of tourism festivals, university libraries, airliners and water taxis $[26,27,28,29]$.

According to Tonge and Moore' s statement, satisfaction, which represents the quality of the user' s experience' was used to draw the quality improvement priorities of the PMIS along with the importance of quality items of the PMIS. That is, we propose to assess the quality improvement priority index(PI) based on the users' assessment of the importance (I) and satisfaction (S) of quality items of the PMIS, on which basis we also determine the quality improvement priorities for the PMS.

\subsection{Quality improvement priority index}

The following are the results reviewing on the priority index to utilize importance and satisfaction presented in the existing literature.

1) Jang and Roh[30] derived the priority using the difference between importance and satisfaction shown in Eq. (1) in order to analyze factors that have an impact on the quality of e-learning contents from the learners' perspective. An equation like this is widely used not only for deriving the priority but also for determining whether there is a difference between two criteria.

$$
P I=I-S^{-----}(1)
$$

Table 2. Example of Priority Index Using (I-S)

\begin{tabular}{cccc}
\hline & Importance & Satisfaction & I-S \\
\hline Quality Factor 1 & 7 & 2 & 5 \\
Quality Factor 2 & 6 & 1 & 5 \\
\hline
\end{tabular}

As shown in Eq. (1), this is the most general and the easiest way to draw the improvement priority based on the difference between importance and satisfaction. However, Table 2 indicates that even though the values of importance and satisfaction are different, if there are two quality items that have the same value in difference, the priority of the two items is shown to be identical, which is a weakness.

2) Eq. (2) is a method widely used to draw the priority along with Eq. (1). As shown in Eq. (2), the two assessment items are shown in a ratio.

$$
P I=\frac{I}{S}-----(2)
$$

Table 3. Example of Priority Index Using (I/S)

\begin{tabular}{lccc}
\hline & Importance & Satisfaction & I/S \\
\hline Quality Factor 1 & 10 & 5 & 2 \\
Quality Factor 2 & 8 & 4 & 2 \\
\hline
\end{tabular}


As in Eq. (1), though the importance and the satisfaction have different values, if there are two quality items that have the same ratio, the improvement priority of the two items is shown to be identical, which is a weakness of Eq. (2).

3) In a study analyzing the improvement priority of the living environment based on residence satisfaction, Park et al.[31] claimed that as it is extreme to determine the items to be improved based only on the satisfaction value, the items should be also considered in the context of the entire living environment. In other words, the weight of each item that takes up the entire living environment assessment (e.g., importance) should also be taken into account. To make the scale standardized, the actual variables were replaced with a relative value compared to the maximum and minimum values. Eq. (3) and Eq. (4) are the standardized formulae for Satisfaction (S) and Importance (I), respectively.

$$
\begin{aligned}
& S=\left(X_{\min }-X_{\max }\right)\left(\frac{x_{\mathfrak{f}}-V_{\min }}{V_{\max }-V_{\min }}\right)+X_{\max } \\
& I=\left(X_{\max }-X_{\min }\right)\left(\frac{x_{\mathfrak{f}}-V_{\min }}{V_{\max }-V_{\min }}\right)+X_{\min }
\end{aligned}
$$

$V_{\max }$ : Maximum value of given scale

$V_{\min }$ : Minimum value of given scale

$X_{\max }$ : Maximum value of standardized scale

$X_{\min }$ : Minimum value of standardized scale

$x_{i}$ : Measured value i'

The Satisfaction and the Importance are standardized as shown in Eq. (3) and Eq. (4), and then Eq. (5) was proposed, which satisfies the following 4 requirements.

(1) The lower the satisfaction is, the higher the priority should be.

(2) The higher the importance is, the higher the priority should be.
(3) If either Importance or Satisfaction has the minimum value, 1 (which means that the standardized value is 1 , when satisfaction is highest and importance is lowest), the need for improvement should be outstandingly low regardless of the values of other factors

(4) The scale of the improvement priority index ranges from 1 to 7 , as does that of Satisfaction and Importance.

$$
P I=\frac{2 I S}{I+S}-----
$$

Table 4. Example of Priority Index Using 2IS/(I+S)

\begin{tabular}{cccc}
\hline & Importance Satisfaction & 2IS/(I+S) \\
\hline Quality Factor 1 & 7 & 5 & 4.2 \\
Quality Factor 2 & 3 & 1 & 4.2 \\
\hline
\end{tabular}

To analyze the priority using Eq. (5), the values of Importance (I) and Satisfaction (S) should be converted. Table 4 shows the priority examples converted according to a 7-point Likert Scale, and as shown in Table 4, some quality items that have different values in Satisfaction and Importance have a priority index.

4) $\mathrm{Yu}$ and Kwon[32] derived the priority of essential success factors by deducing the success factors in urban regeneration projects and analyzing the differences through research on Importance and Satisfaction. They have the same rationale that the higher the difference between Importance and Satisfaction, and the higher the ratio is, the higher the priority should be, but they also maintained that the priority cannot be fully explained and supported when derived using only the individual differences and ratios. Therefore, they proposed Eq. (6), in which the difference between and the ratio of 
Importance (I) and Satisfaction (S) are reflected simultaneously.

$$
P I=(I-S) \times(I \div S)------(6)
$$

Table 5. Example of Priority Index Using (I-S)(I/S)

\begin{tabular}{cccc}
\hline & Importance & Satisfaction & $(\mathrm{I}-\mathrm{S})(\mathrm{I} / \mathrm{S})$ \\
\hline Quality Factor 1 & 6 & 2 & 12 \\
Quality Factor 2 & 4 & 1 & 12 \\
\hline
\end{tabular}

However, as in Table 5, Eq. (5) has a similar problem, as even when using this equation, there are some cases that have an improvement priority index.

The four different types of approaches for assessing the improvement priority index based on Importance and Satisfaction are generally used, or an approach is newly proposed that is appropriate for the research objective. Although there are differences among the four types of assessment method mentioned above, the methods have one thing in common, which is the fundamental assumption that the higher the satisfaction and the lower the importance, the higher the priority should be. However, as indicated above, two different items assessed to have different values in Importance and Satisfaction can have a priority index. This is the limitation of the improvement priority index in terms of priority discrimination, which is the fundamental requirement.

\section{Assessment of quality improvement priorities}

\subsection{Quality improvement priority index for the PMIS}

In order to address the limitations of the assessment method of improvement priority explained in Section 2.3, the premises of PI for this research are as follows. First, when Satisfaction is shown to be low compared to Importance (I>S), the priority is set for the quality items. Second, the lower the redundancy (that is, the better the discrimination), the better the PI. The purpose of the PI comprised of Importance (I) and Satisfaction (S) proposed in this research is to determine the individual priority of 23 quality items in Section 2.1, and it should meet the two requirements below.

(1) When more than two quality items have the same value in the areas of Importance and Satisfaction, the higher the Importance value, the higher the priority. The $P I_{1}$ that meets this requirement is expressed as follows:

$$
P I_{1} \propto I(I-S)----(7)
$$

(2) When more than two quality items have the same value in terms of the difference between Satisfaction and Importance, the lower the satisfaction, the higher the priority. The $\mathrm{PI}_{2}$ that meets this requirement is expressed as follows:

$$
P I_{\check{L}} \propto \frac{1}{S}(I-S)
$$

The PI that simultaneously reconciles the two requirements can be obtained by combining Eq. (7) and Eq. (8). The weighted aggregation most widely used in combining individual indices was utilized in this study. Under the hypothesis that the weight of an individual index is equal according to Eq. (7) and Eq. (8), the quality improvement priority index is suggested as shown in Eq. (9).

$$
P I=I(I-S)+\frac{1}{S}(I-S)_{-----}
$$

\subsection{Verification of discrimination of the PI}

To conduct a comparative analysis of the PI proposed in this research and the four different types of priority assessment methods discussed in Section 2.2, Table 6 enumerates the indexes and 
Table 6. Discrimination Comparative Analysis of Improvement Priorities Index (7 point Likert scale)

\begin{tabular}{|c|c|c|c|c|c|c|c|c|c|c|c|c|}
\hline \multirow{2}{*}{$\begin{array}{c}\text { Quality } \\
\text { Factor } \\
\text { No. }\end{array}$} & \multirow{2}{*}{ I } & \multirow{2}{*}{$S$} & \multicolumn{2}{|c|}{ Formula-(1) } & \multicolumn{2}{|c|}{ Formula-(2) } & \multicolumn{2}{|c|}{$\begin{array}{l}\text { Formula-(5) } \\
2 \mid S /(\mid+S)\end{array}$} & \multicolumn{2}{|c|}{$\begin{array}{l}\text { Formula-(6) } \\
(\mid-S)(I / S)\end{array}$} & \multicolumn{2}{|c|}{$\begin{array}{l}\text { Formula-(9) } \\
(I-S)(I S+1) / S\end{array}$} \\
\hline & & & $\mathrm{Pl}$ & RANK & $\mathrm{Pl}$ & RANK & $\mathrm{PI}$ & RANK & $\mathrm{PI}$ & RANK & $\mathrm{Pl}$ & RANK \\
\hline 2 & 7 & 2 & 5 & 2 & 3.500 & 5 & 6.462 & 2 & 17.500 & 4 & 37.500 & 2 \\
\hline 3 & 7 & 3 & 4 & 3 & 2.333 & 8 & 5.833 & 4 & 9.333 & 6 & 29.333 & 4 \\
\hline 4 & 7 & 4 & 3 & 4 & 1.750 & 10 & 5.091 & 6 & 5.250 & 9 & 21.750 & 7 \\
\hline 6 & 7 & 6 & 1 & 6 & 1.167 & 17 & 3.111 & 13 & 1.167 & 19 & 7.167 & 16 \\
\hline 7 & 6 & 1 & 5 & 2 & 6.000 & 2 & 6.462 & 2 & 30.000 & 2 & 35.000 & 3 \\
\hline 8 & 6 & 2 & 4 & 3 & 3.000 & 6 & 6.000 & 3 & 12.000 & 5 & 26.000 & 5 \\
\hline 9 & 6 & 3 & 3 & 4 & 2.000 & 9 & 5.455 & 5 & 6.000 & 8 & 19.000 & 8 \\
\hline 10 & 6 & 4 & 2 & 5 & 1.500 & 12 & 4.800 & 8 & 3.000 & 12 & 12.500 & 12 \\
\hline 11 & 6 & 5 & 1 & 6 & 1.200 & 16 & 4.000 & 11 & 1.200 & 18 & 6.200 & 17 \\
\hline 12 & 5 & 1 & 4 & 3 & 5.000 & 3 & 5.833 & 4 & 20.000 & 3 & 24.000 & 6 \\
\hline 14 & 5 & 3 & 2 & 5 & 1.667 & 11 & 5.000 & 7 & 3.333 & 11 & 10.667 & 13 \\
\hline 15 & 5 & 4 & 1 & 6 & 1.250 & 15 & 3.750 & 12 & 1.250 & 17 & 5.250 & 18 \\
\hline 16 & 4 & 1 & 3 & 4 & 4.000 & 4 & 5.091 & 6 & 12.000 & 5 & 15.000 & 10 \\
\hline 17 & 4 & 2 & 2 & 5 & 2.000 & 9 & 4.800 & 8 & 4.000 & 10 & 9.000 & 14 \\
\hline 18 & 4 & 3 & 1 & 6 & 1.333 & 14 & 4.444 & 9 & 1.333 & 16 & 4.333 & 19 \\
\hline 19 & 3 & 1 & 2 & 5 & 3.000 & 6 & 4.200 & 10 & 6.000 & 8 & 8.000 & 15 \\
\hline 20 & 3 & 2 & 1 & 6 & 1.500 & 12 & 4.000 & 11 & 1.500 & 15 & 3.500 & 20 \\
\hline 21 & 2 & 1 & 1 & 6 & 2.000 & 9 & 3.111 & 13 & 2.000 & 14 & 3.000 & 21 \\
\hline \multicolumn{3}{|c|}{ Discrimination } & \multicolumn{2}{|c|}{6} & \multicolumn{2}{|c|}{17} & \multicolumn{2}{|c|}{13} & \multicolumn{2}{|c|}{19} & \multicolumn{2}{|c|}{21} \\
\hline
\end{tabular}

priorities of each method. For the comparative analysis, I and S were set fit for the 7-point Likert Scale, and a total of 21 cases were also set to satisfy the premise of $\mathrm{I}>\mathrm{S}$.

To compare the discrimination of each method, each method was analyzed to determine how sharply it could discriminate the 21 cases. As you can see in Table 6, the 21 cases fell into 6 priorities under Eq. (1), 17 priorities under Eq. (2), 13 priorities under Eq. (5), and 19 under by Eq. (9), which is relatively more discriminated compared with the existing methods.

\section{Quality improvement priorities and plan for the construction PMIS}

\subsection{Summary of quality improvement priorities assessment}

To assess the extent to which the quality improvement priorities reflected the opinions of the users of a construction PMIS in Korea, a total of 23 assessment items of three PMIS quality factors were measured using a 7-point Likert scale. A questionnaire survey was conducted for the operators and construction managers that are the main users of a construction PMS. Data collection using a questionnaire was carried out over about 3 months from May 10, 2010 to August 9, 2010 via e-mail and postal mail. Average daily time the respondents spent using PMIS stood at 4.69 hours, which was sufficiently long for them to assess the quality of PMIS. Table 7 shows the general information of the 253 respondents.

\subsection{Analysis of quality improvement priorities}

For the analysis of the quality improvement priorities of the construction PMIS, the average of the points assessed by 253 respondents were used as the values of I and $\mathrm{S}$. The priority analysis was determined using Eq. (9), and Table 8 shows the 
analytical results of improvement priorities. It is hypothesized that when the value of Importance is less than that of Satisfaction, the user is satisfied with the quality item, and thus he/she does not place any emphasis on improvement. That is, when the value of Importance is less than that of Satisfaction, the value of PI is shown to be ' 0 ' or negative, and such items are considered as not included in the priorities analysis.

Table 7. Characteristics of The Respondents $(n=253)$

\begin{tabular}{|c|c|c|c|}
\hline \multicolumn{2}{|c|}{ Description } & Frequency & $\%$ \\
\hline \multirow{2}{*}{ Project Type } & Public Project & 113 & $44.7 \%$ \\
\hline & Private Project & 140 & $55.3 \%$ \\
\hline \multirow{2}{*}{ User Type } & $\mathrm{CM}$ & 140 & $55.3 \%$ \\
\hline & Contractors & 113 & $44.7 \%$ \\
\hline \multirow{5}{*}{$\begin{array}{c}\text { Experience } \\
\text { in } \\
\text { Construction }\end{array}$} & Less than 2 years & 42 & $16.60 \%$ \\
\hline & $3 \sim 5$ years & 41 & $16.21 \%$ \\
\hline & $5 \sim 10$ years & 53 & $20.95 \%$ \\
\hline & $10 \sim 15$ years & 27 & $10.67 \%$ \\
\hline & More than 15years & 90 & $35.57 \%$ \\
\hline \multicolumn{2}{|c|}{ Respondents' Average PMIS Use } & \multicolumn{2}{|c|}{4.69 hours/day } \\
\hline
\end{tabular}

Table 8. Analysis of Improvement Priorities

\begin{tabular}{|c|c|c|c|c|}
\hline \multirow{2}{*}{ NO } & \multirow{2}{*}{ I } & \multirow{2}{*}{ S } & \multicolumn{2}{|c|}{$(I-S)(I S+1) / S$} \\
\hline & & & $\mathrm{Pl}$ & RANK \\
\hline SyQ1 & 3.73 & 3.66 & 0.280 & 11 \\
\hline SyQ2 & 3.09 & 3.04 & 0.171 & 13 \\
\hline SyQ_3 & $\underline{4.33}$ & $\underline{4.06}$ & $\underline{1.236}$ & 1 \\
\hline SyQ4 & 4.38 & 4.38 & 0.000 & 16 \\
\hline$\underline{S y Q 5}$ & $\underline{4.13}$ & $\underline{3.89}$ & $\underline{1.053}$ & $\underline{3}$ \\
\hline InQ_1 & 4.12 & 3.96 & 0.700 & 7 \\
\hline InQ_2 & 4.16 & 3.98 & 0.794 & 6 \\
\hline InQ_3 & 3.92 & 3.98 & -0.250 & 17 \\
\hline InQ_4 & 3.89 & 3.78 & 0.457 & 8 \\
\hline InQ_5 & 4.25 & 4.16 & 0.404 & 9 \\
\hline$\underline{\ln Q \_6}$ & $\underline{4.11}$ & $\underline{3.84}$ & $\underline{1.180}$ & $\underline{2}$ \\
\hline$\underline{\ln Q \_7}$ & $\underline{4.13}$ & $\underline{3.90}$ & $\underline{1.009}$ & $\underline{5}$ \\
\hline InQ_8 & 4.15 & 4.07 & 0.352 & 10 \\
\hline InQ_9 & 3.85 & 3.85 & 0.000 & 16 \\
\hline InQ_10 & 3.79 & 3.75 & 0.162 & 14 \\
\hline SeQ_1 & 3.74 & 3.94 & -0.799 & 18 \\
\hline SeQ_2 & 3.74 & 3.99 & -0.998 & 20 \\
\hline$\underline{\mathrm{SeQ} 3}$ & 3.57 & $\underline{3.30}$ & $\underline{1.046}$ & $\underline{4}$ \\
\hline SeQ_4 & 3.66 & 3.63 & 0.118 & 15 \\
\hline SeQ 5 & 3.73 & 3.66 & 0.280 & 11 \\
\hline SeQ_6 & 3.59 & 3.82 & -0.886 & 19 \\
\hline SeQ_7 & 3.96 & 3.96 & 0.000 & 16 \\
\hline SeQ_8 & 4.18 & 4.14 & 0.177 & 12 \\
\hline
\end{tabular}

Of the analytical results, the top 30 percent of 16 items except for the 7 quality items that meet the condition of $\mathrm{I}-\mathrm{S} \leq 0$ are shown as follows:

$1^{\text {st }}$ place (SyQ-3) easy input and output of data on the system (upload/download, print out, etc.)

$2^{\text {nd }}$ place (InQ-6) availability of data provided from the system without correction

$3^{\text {rd }}$ place (SyQ-5) stability of the system at a given time

$4^{\text {th }}$ place (SeQ-3) provision of appropriate education to users

$5^{\text {th }}$ place (InQ-7) adequate amount of information provided from the system

\subsection{Improvement plans of quality items ranked at top}

To derive the quality improvement plans for the top 5 quality items in the analytical results of quality improvement priorities for the construction PMIS, a written survey was administered to 8 specialists with at least 10 years of experience employed in 3 companies providing construction ASP-PMISs. The five quality items mentioned above were presented with the comment that they were obtained from the assessment result of I and S by 253 users. The 8 specialists were asked to describe the potential reasons why the users prioritized those items, and the plan to improve the quality of those items. We expected the developer to come up with improvement plans as well as the reasons for those items being selected from the users' perspective. The improvement plans for the five items discussed through the procedure above are shown as follows.

\subsubsection{System quality}

1) Improvement plan for [SyQ-3: easy input and output of data on the system (upload/download, print out, etc.)] 
- Unify the data entry window to enhance user convenience

- Improve the document sorting system and provide an integrated viewer that enables the system to incorporate various document formats

- Standardize the different forms of documents and the approval system to be utilized on the system

- Provide a function for compatibility with existing document preparation software (e.g. Hansoft Office, MS Word, etc.)

2) Improvement plan for [SyQ-5: stability of the system at a given time]

- Desirable to use a specialized server rental service to secure stability of the server

- Make efforts to minimize the shut-down of the system caused by correction work under operation. It is particularly important to fully review the plan at the preparation stage.

- When a correction is needed during operation, allot sufficient time and prepare for the correction thoroughly in order to ensure that no additional corrections are needed.

\subsubsection{Information quality}

3) Improvement plan for [InQ-6: availability of data provided from the system without correction]

- Design the architecture of the system after a thorough analysis of the actual working process, in order to reflect the working process of the users to the greatest extent possible

- Improve the functions of the system to keep up with the actual working process based on further tests after the development of the system

- Define the type and format of related information and the form needed in the early stage of the project

- Enhance the accuracy of the information generated in the course of working by providing the auto-alarm function for the task to be fulfilled

- Increase the availability of the information by providing diverse reporting functions on the information and data/document content created

4) Improvement plan for [InQ-7: adequate amount of information provided from the system]

- Expand the functions to utilize the results analysis and the outlook on the future and past data, beyond simply accumulating the input data on the system in the process of performance

- Selectively input data useful for storing or sharing in the field through continuous communication with practitioners

- At the development of the system, provide users with thorough training on the method and information type for each module

- Design the system comprehensively, taking into account the information creation and utilization process

- By utilizing the PMS in the entire organization as well as in an individual project, the amount of information accumulated and utilized can be increased

\subsubsection{Service Quality}

5) [SeQ3: provision of appropriate education to users]

- Design a system that users can use intuitively through multiple tests in the early stage of system building

- Develop and provide distance learning material or manuals to overcome the weaknesses of direct training for users

- Need to develop appropriate education for usage and manuals by user attributes (position, task, etc)

- Lay the groundwork of the project management by utilizing a system that includes PMIS-related 
learning in the university curriculum

- Enhance the education effect by providing regular education on the system and periodic information on the system upgrade

\section{Conclusion}

As the need for and utilization of construction PMIS has been on the rise, regular quality assessment from the user' $\mathrm{s}$ perspective enables developers to understand user requirements in order to ensure the utilized construction PMIS is appropriate for its purposes. For this reason, a quality improvement priority index was presented using the concepts of Importance and Satisfaction, on which basis the priorities for the improvement of the construction PMIS were drawn. The improvement plans of the quality items ranked at the top of the list were also discussed.

1) Quality items were presented in order to assess the quality improvement objects of the construction PMIS. The reliability of the quality items was statistically verified and confirmed based on the assessment items drawn from the literature, and a total of 23 quality assessment items of construction PMIS were presented.

2) As factors to assess the quality improvement objects of the construction PMS, Importance and Satisfaction were presented, and methods to determine priority index were also suggested. The newly proposed method was verified to have higher discrimination power than the existing methods.

3) With the quality assessment items, assessment factors, and priority index calculation method, the quality improvement priorities of the ASP PMIS widely used in the construction industry in Korea were analyzed. For the analysis, data was collected from 253 users through a questionnaire. Improvement plans for the top 5 items according to the calculated priority index were proposed based on the opinions of 8 specialists in PMS development.

This research has significance, in that the quality improvement priorities of the construction PMIS in wide use were presented using a priority index with discrimination power that had been verified statistically. In addition, improvement plans were also presented based on the opinions of specialists. However, the determination of the improvement items according to priority was expedient for efficient improvement due to the limitations of resources, and it is inevitably necessary to perform continuous activities to improve the system quality. Furthermore, the numerical value calculated in this study can vary depending on the measuring tools and methods, so while it can be utilized to determine the relative urgency of assessment items, it is impossible to conduct absolute interpretation.

To perform continuous quality improvement of the construction PMS, this quality improvement priority assessment should not be just a one-time event, as continuous assessment, improvement activities and feedback processes are needed. A system should be built that enables the construction PMIS to be continuously improved, and the systematic management of the quality improvement priority assessment is also required. In addition, by comparing the assessment values between an individual PMIS and all PMISs, or between individual PMISs, individual PMIS providers will be motivated to improve their system. A priority assessment method that reflects the relative importance of individual quality items should be considered. 


\section{Acknowledgement}

The present Research has been conducted by the Research Grant of Kwangwoon University in 2010

\section{References}

1. $\mathrm{Yu} \mathrm{JH}$. [Status and Expectation of Construction Project Management Information System]. Journal of Architectural Institute of Korea. 2006 Oct;50(10):25-7. Korean.

2. Lee HS, Lee BN, Kim WY, Yu JH, Song SH. [Construction company PMIS assessment and development strategies research]. Seoul(Korea): Construction \& Economy Research Institute of Korea; 2005. 108 p. Korean.

3. Moon JH, Song BG. [PMIS Solution in the Korea Construction Industry]. Seoul(Korea): Construction \& Economy Research Institute of Korea; 2003. 53 p. Korean.

4. Han CH, Kim JK, Choi SH, Kim SH. Determination of Information System Development Priority Using Quality Function Deployment. Proceedings of the 23rd International Conference On Computers and Industrial Engineering;1998 Mar 28-Apr 2; Chicago, IL. New York (NY): Elsevier Science Ltd; 1998. p. 241-44.

5. Bacon JC. The Use of Decision Criteria in Selecting Information Systems/ Technology Investments. MIS Quarterly. 1992 Sep;16(3):335-53.

6. Burch JG. Planning and Building Strategic Information Systems. Journal of Systems Management. 1990 July;41(7):21-7.

7. Ahituv N, Neumann S. Principles of Information Systems for Management. 2nd ed. Dubuque(IA): William C Brown; 1986. $704 \mathrm{p}$.

8. Kim WH. Determining IT Investment Priorities via AHP: a case study [master's thesis]. Seoul (Korea): KonKuk University; 2009. 112 p.

9. Kyung TW, Kim SK. Priority Analysis of Information System by the Stakeholders using BSC and ANP Method. The Journal of the Korea Contents Association. 2011 Mar;11(7):426-35.

10. Lee SK, $\mathrm{Yu}$ JH. Critical Success Factors for Project Management Information System in Construction. Journal of construction engineering and Project Management. 2011 May;1(1):25-30

11. Park JH, Kim JG, Kim JW, Lee HS. Deriving an ASP Success Model: An Application to Small Businesses. Asia
Pacific Journal of Information System. 2004 Mar;14(1):4358.

12. Jung YS, Jung CH. An Empirical Analysis on the Success Factors of ASP Services. Korea Association of Information System. 2005 Feb;14(2):25-53.

13. Kim G. A Scale Development for Measuring User Satisfaction with GKMS. Journal of the korea Association for Policy Analysis and Evaluation. 2007 Dec;17(4):117-148.

14. Jeo MH, Lee CK. An Empirical Analysis on Success Factor and Success Model of Information System: Focus on a local government. Journal of Korea Administration. 1997 Spring;31(1):145-62.

15. Edward JG, Glassberg B, Kim YJ, Lawrence S, Shin SK. An experimental investigation of Web-based information systems success in the context of electronic commerce. Decision Support Systems. 2005 May;39(3):485-503.

16. Liu C, Arnett KP. Exploring the factors associated with web site success in the context of electronic commerce. Information \& Management. 2000 Oct;38(1):23-33.

17. Han YC, Lim ST. An Empirical Study on Evaluating Effectiveness of Information System. Journal of Business Research. 1997 Jan;12(1):257-88.

18. Ballou DP, Pazer HL. Cost/quality tradeoffs for control procedures in information systems. Omega. 1987 Sep;15(6):509-21.

19. Parasuraman A, Zeithaml VA, Berry LL. SERVQUAL: A multiitem scale for measuring consumer perceptions of service quality. Journal of Retailing. 1988 Mar;64(1):12-40.

20. Norusis MJ. SPSS for windows: Professional Statistics Release 5. 5th ed. Chicago(IL): SPSS Incorporated; 1992. $348 \mathrm{p}$.

21. Li B, Akintoye A, Edwards PJ, Hardcastle C. Critical success factors for $\mathrm{PPP} / \mathrm{PFI}$ projects in the UK construction industry. Construction Management and Economics. 2005 Jun;23(5):459-71.

22. Aksorn T, Hadikusumo BHW. Critical success factors influencing safety program performance in Thai construction projects. Safety Science. 2008 Apr;46(4):70927.

23. Nunnally JC. Psychometric theory. 2nd ed. New York (NY): McGraw-Hill; 1978. 701 p.

24. Matilla, JA. James, JC. Importance-Performance analysis. Journal of Marketing. 1977 Jan;41(1):77-9.

25. Tonge J, Moore SA. Importance-satisfaction analysis for marine-park hinterlands: A Western Australian case study. 
Tourism Management. 2007 Jun;28(3):768-76.

26. Park SH, Kwak DY, Chung BW. Importance-Satisfaction Analysis of Tourist Gala: Evaluation of Boryong Mud Festival. The Tourism Sciences Society of Korea. 2008 Aug;32(4):145-66.

27. Park JW, Lee YS, Park KW. A study on the Importance and Satisfaction of Airline Service Quality. The Journal of the Korea Contents Association. 2008 Feb;8(2):164-72.

28. Jung YM, Kim YK, Lee SS. A Study on the Measurement and Improvement of Academic Library Service Quality by ISA(Importance-Satisfaction Analysis). Journal of Korean Library and Information Science Society. 2010 Mar;41(1):255-72..

29. Kim TH, Ha JM, Lim JM, Park JJ. An analysis on indicator of water taxi user service in seoul using Importance Performance Analysis(IPA). Journal of korean society of civil engineers. 2009 Sep;29(5):587-95.

30. Jang SY, Roh SZ. Factors Influencing the Quality of Elearning Contents Provided by the Universities at the Learners' Perspectives. Korean Society for Internet Information. 2009 Jun;10(3):159-72,

31. Park IS, Kang IH, Kang BS. An Analytic Method determining Improvement Priorities for the Housing Environments by Residents' Satisfaction. Journal of Architectural Institute of Korea. 1993 Jun;9(6):9-18.

32. $\mathrm{Yu} \mathrm{JH}$, Kwon HR. Critical Success Factor for Urban Regeneration Projects in Korea. International Journal of Project Management. 2011 Oct;29(7):889-99. 